\title{
Selecting a material for an aircraft diesel engine block
}

Selecting appropriate materials is presently a complex task as material databases cover tens of thousands of different types of materials. Product designing proceeds in numerous stages and in most of them there are open questions with not only one correct solution but better and worse ones. This paper overviews the Diesel engine body construction materials mentioned in the literature and discusses a certain practical method to select materials for a cylinder head and a Diesel engine block as a prototype. The engine body, depending on its purpose, is most frequently iron or aluminum. If it is important to optimize parts to achieve low weight, aluminum alloys are usually applied, especially in the automotive and aviation industries. In the latter case, weight is even more important so new types of magnesium alloys which are even lighter than aluminum ones are developed and used. However, magnesium alloys are, for example, more flammable and not enough strong so, for safety reasons, this type of material is not used solely in engine bodies.

Key words: Diesel, engine, aluminum alloys, engine block, prototype

\section{Introduction}

The choice of a material for the combustion engine block discussed in this paper is directly related to the designing research on a new type of combustion engine structure done in cooperation with the Construction Office of WSK PZL-KALISZ S.A. The investigated engine is a newly designed two-stroke internal diesel engine. The unit's characteristic feature is three cylinders with three pairs of opposed-pistons (Fig. 1). The engine will generate a power output equal to $100 \mathrm{~kW}$ at a crankshaft rotation speed of $3800-4000 \mathrm{rpm}$ with a capacity of about 1.61 in a diesel cycle. The engine will be equipped with a direct diesel injection system. The progress in this research is described in $[4,5,11,16]$.

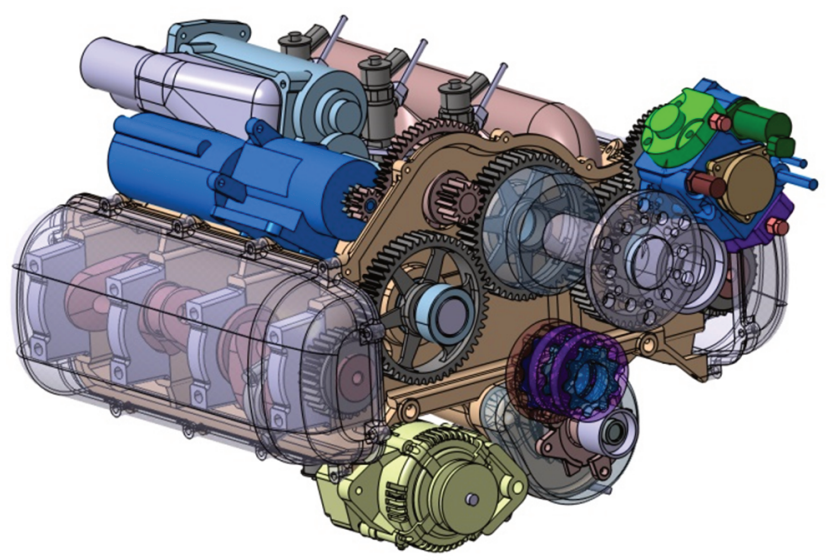

Fig. 1. Visualization of the new construction of the opposed-piston engine

Nowadays, material databases count tens of thousands of different materials so selecting an appropriate structural material is a complex task. Product designing is a multistep process. Most of these steps face open problems where is no only one correct solution but better and worse ones. The idea of material selection charting introduced in [1] helps in an initial material selection and enables a logical procedure to be used in next stages of such a selection. A type of project (original, adaptive or alternative) already enables a group of desired materials to be initially narrowed down. As far as the original design is expected to be innovative in terms of its materials, an alternative design does not have to be so if its functions are preserved and its modifications involve scale, dimension or a manner to achieve its function. The body of the two-stroke compressionignition engine can be just classified as an alternative type of design. Cylinder heads and piston engine blocks are usually made of cast iron or aluminum alloys to match their purpose. If it is important to optimize parts for the lowest possible weight, aluminum alloys are usually used, which is typical of the automotive and aviation industries. Actually, in aviation, weight is even more important so new magnesium alloys which are lighter than aluminum alloys are used, however their flammability, lower strength and safety reasons make this material not be used on its own in engine bodies.

World War I and II were heyday periods for the aircraft piston engine. Then, the development of the jet engine hampered their progress for many years. Nowadays, the piston engine is chiefly used in light aircraft: aero clubs, business, cargo, rescue, sport and recreation. Technically, these engines show a pre-war knowledge of theory of operation, design and production technology, especially in comparison with today's automotive drives [14].

According to [14] piston engines constitute the largest weight in every aircraft. Unit weight, or weight per unit of power, used in today's aircraft piston engines is 3-4 times larger than in turbine engines. Individual values of characteristic parameters are: fuel consumption $200-220 \mathrm{~g} / \mathrm{km} / \mathrm{h}$, power cylinder capacity: $50-60 \mathrm{KM} / \mathrm{dm}^{3}$, weight: $\sim 0.5$ $\mathrm{kg} / \mathrm{KM}$. These values relate to spark-ignition engines. Compression-ignition engines due to technological difficulties were not very popular in aviation in the last century and were often used in tanks.

Therefore, this topic is very interesting because light civil aviation is gaining in importance and environmental aspects are crucial here. This is an opportunity to develop aircraft piston engines and apply certain verified automotive solutions because piston engines are constantly improved to satisfy ecological requirements. Currently, compression-ignition engines are increasingly used in the light aviation, e.g. ZOCHE aero-diesel, Wilksch Airmotive, 
DeltaHawk Engines, Gemini Diesel, DAIR-100 Diesel Air, Austro Engine AE300 or the conceptual engine by Baker Engineering and Kinetic BEI LLC.

Finding a strong enough type of material to satisfy loads expected in the designed engine is relatively easy. However, finding an optimal solution is not so. It is possible to use alloys which are used, for example, in military applications but their price prevents civil ones. According to [9], a single turbine blade made of a nickel-cobalt alloy known as Inconel is 10 thousand dollars. Piston engines have no blades but have elements that should transfer significant thermal stress.

\section{Methodology}

A number of material available exceeds capabilities of selection if we resort to analytical capabilities of the human mind only. A kind of software that collects database for specific materials appear to be helpful here. This is an attractive though a very expensive solution, which greatly limits its usefulness [1]. It is worth noting that the approach to the issue of selecting materials presented at least in technical university courses [17] cannot be applied if there is a real need to design elements and select the right material for a designed alternative product. As indicated in [17], selecting materials is an optimization process, so it is necessary to formulate constraints and functions defining material requirements, which means finding the so-called functionality indicator dependent on properties of a material and whose maximization determines an optimal material for a given purpose. This approach is accurate mainly if simple, original products are designed as it enables us to extend an application of new materials.

The functionality indicator is determined from the following algorithm [17]:

- determining the feature to be optimized,

- deriving the equation of the feature to show functional requirements - the function of the objective,

- determining design constraints,

- deriving equations representing design constraints,

- determining free variables,

- substituting free variables calculated from (d) into equation (b),

- grouping the variables into three sets: functional (loads, deflections ...), geometric (size, moments of inertia of sections ...) and material (properties)

- reading the functional indicator.

These are basic guidelines which should be accompanied by other factors like price, ownership of a technology or an ecological impact. In practice, especially if selecting materials for engine components, materials cannot be correctly and effectively selected with no expert knowledge of operations and processes, even if resorting to databases. A simple specification of loads acting on so complex elements that are subjected to variable stress and thermal loads is impossible either. This is verified just after entering material parameters into simulation software, for example parameters that determine mechanical stress or thermal load and after the computation. Accurate calculations are timeconsuming, so performing hundreds of repeated calculations for other materials is simply impossible. If load is not known yet, a pre-received material should be adopted. It is, therefore, indispensable to determine what materials could be used for the aircraft piston engine block. Instead of formulating theoretical functionality indicators, time-consuming and complicated to determine loads acting on the product, you can collect information on what materials have been used so far for given elements and choose those that meet requirements set for designed parts, e.g. the engine as it is here. Additional aspects to consider are, of course, availability, price or knowledge and a possibility of an economically justified processing of a given material. This solution should be avoided while designing [1], especially the original product as it hampers development in the field of applied materials. Here, however, we have an adaptive product which is a part of a larger project of a present period of time, fixed-cost, and a necessary level of quality. It seems reasonable here to limit oneself above all to available materials and not search for and test expensive and unreachable ones. It should also be remembered that if you decide on a material not used in a given field yet, you can face new problems such as no accurate material data at given loads, which may lead to significant difficulties and a longer selection period of time, which will also affect quality of calculations. Another important issue is a machining of the material. One can think that companies that professionally manufacture engine components should not find it as a significant problem. The necessity of retooling machines, extending a preparation and completion period of time means high costs and may affect mass production. Mass production companies are hardly interested in unit production, and the need for retooling their technological machines causes a dramatic increase in cost of production. If a prototype project is developed under a research project or by a research center, it becomes another issue affecting a choice of a material. It is necessary to prepare adequate technological facilities to implement production processes.

The first phase of the product life cycle, including manufacturing prototype parts, is very expensive in the whole life-cycle. For example, a unit production of a piston engine with a diameter of a few centimeters in line with a target producing technology amounts to tens of thousands of Polish zlotys. It consists of all production processes that occur during a standard serial production. If there are certain exemptions from a basic technology, this cost can be reduced by up to $80 \%$, however, such a product will probably show poorer strength than its equivalent produced in series. While developing the prototype, some exemptions are necessary chiefly to enable the creation and testing of different versions of parts, and an improvement of the process is postponed in line with the Pareto principle, i.e. $80 \%$ of the results come from $20 \%$ of outlay and $20 \%$ of the results should be covered by $80 \%$ of outlay. This principle describes many economics and management phenomena.

In this work, literature analysis is a main tool to select a material for a prototype engine block; however, aircraft engine manufacturer's experience and technological resources are used, too. First, our focus was on the previously used materials for the given element both in the automotive and aviation industries. Then, the development of materials was studied, focusing on selected properties, which accord- 
ing to the authors are fundamental, if not decisive here. Also, the authors included availability and data obtained from the material database.

\section{Application of aluminum alloys in the production of diesel engine blocks}

\subsection{Designation}

Depending on the source of the article and the time it was written, aluminum alloys have different designation. In order to unify the nomenclature in situations where there is an equivalent in European standards for:

- PN-EN 573 "Aluminum and aluminum alloys - Chemical composition and types of plastically processed products"

or

- PN-EN 1706 "Aluminum and aluminum alloys - Castings - Chemical composition and mechanical properties"

it will be quoted, but due to differences in the content ranges of individual elements for individual alloys, this is not always possible. Then the original nomenclature will be preserved, and possibly the material with the closest composition will be indicated. Below, Table 1 and 2 present exemplary markings of aluminum alloys in standards most frequently used by manufacturers and in scientific publications.

Table 1. Designation of plastic processed aluminum alloys according to selected standards [8]

\begin{tabular}{|c|c|c|c|c|}
\hline $\begin{array}{c}\text { PN EN } \\
573-3 \\
\text { (numerical) }\end{array}$ & $\begin{array}{c}\text { PN EN } \\
\text { (chemical) }\end{array}$ & $\begin{array}{c}\text { PN-79/H-82160 } \\
\text { (old norm) }\end{array}$ & ASTM & DIN \\
\hline 2017A & $\begin{array}{c}\text { AlCu4MgSi } \\
\text { (A) }\end{array}$ & PA 6 & 2017 & $\begin{array}{c}\text { Al- } \\
\text { CuMg1 }\end{array}$ \\
\hline
\end{tabular}

Table 2. Designation of aluminum alloys castings according to selected standards [10]

\begin{tabular}{|c|c|c|c|}
\hline PN-EN & PN-76/H-88027 (old & ISO & EN \\
$1706: 2001$ & norm) & $3522 / 1984$ & $1706: 1998$ \\
\hline \multirow{2}{*}{ AC-AlSi7Mg } & AK7 & Al- & AC- \\
& AlSi7Mg & Si7Mg/Fe/ & AlSi7Mg \\
\hline
\end{tabular}

Aluminum alloys are thermally treated to the state $\mathrm{T}$. The designation together with the description is presented in Table 3. In the context of engine block and cylinder head machining, T6 treatment is the most common.

Table 3. Designation of heat treatment process conditions [6]

\begin{tabular}{|c|l|}
\hline $\begin{array}{c}\text { Treatment } \\
\text { designation }\end{array}$ & \multicolumn{1}{c|}{ Treatment description } \\
\hline T1 & $\begin{array}{l}\text { naturally aged after cooling from the increased tem- } \\
\text { perature of the shaping process }\end{array}$ \\
\hline T2 & $\begin{array}{l}\text { cold deformed after cooling from elevated forming } \\
\text { temperature and naturally aged }\end{array}$ \\
\hline T3 & over-saturated, cold deformed and naturally aged \\
\hline T4 & saturated and naturally aged \\
\hline T5 & $\begin{array}{l}\text { artificially aged after cooling from an elevated tem- } \\
\text { perature of the shaping process }\end{array}$ \\
\hline T6 & saturated and artificially aged \\
\hline T7 & saturated and stabilised (obsolete) \\
\hline T8 & over-saturated, cold deformed and artificially aged \\
\hline T9 & over-saturated, artificially aged and cold deformed \\
\hline
\end{tabular}

\subsection{Materials used in the manufacture of diesel engine blocks}

In the popular scientific literature, in the context of materials used to manufacture the engine body (depending on the construction this refers to the engine block and cylinder head), most often appear aluminum alloy or wrongly aluminum, which actually replaced the older and heavier cast iron constructions. However, in the engine design process the information about an unspecified alloy is definitely insufficient, detailed data of a specific material are necessary. Engine manufacturers often do not provide information about the type of alloy used, its properties or the type of treatment used. The "know-how" in cylinder head casting technology is closely guarded and provides an advantage in the market.

The cylinder heads must fulfil two basic material requirements. One of them is resistance to deformation caused by the pressure generated during combustion of the load and assembly loads preventing leaks in the system. The second requirement is resistance to high temperatures to prevent cracks in the cylinder head area between inlet and outlet valves, which are exposed to flame [15].

According to the material base [10], the following alloys can be used for cylinder heads of combustion engines:

- AK52 (AlSi6Cu2),

- AK51 (AlSi5Cu1),

- AK84 (AlSi8Cu4MgMn) (air cooling, Fiat 126p),

- AK53 (AlSi5Cu3Mn).

However, there are situations where producers decide to make their knowledge available to a wider audience. In the paper [13] the tested materials used for the production of cylinder heads are alloys:

- AK51 (AlSi5Cu1)

and

- alloy composed of $8.75 \% \mathrm{Si}, 0.50 \% \mathrm{Cu}, 0.43 \% \mathrm{Mg}$, $0.13 \% \mathrm{Mn}, 0.22 \% \mathrm{Fe}, 0.02 \% \mathrm{Ni}, 0.03 \% \mathrm{Zn}, 0.02 \% \mathrm{Ti}$, $0.02 \% \mathrm{Sn}$, with a composition close to the alloy AK9 $(\mathrm{AlSi} 9 \mathrm{Mg})$ with a content of $8.5-10.5 \% \mathrm{Si}, 0.3 \% \mathrm{Cu}$, $0.25-0.4 \% \mathrm{Mg}, 0.25-0.5 \% \mathrm{Mn}$.

It is described as a material of the "head of a wellknown automotive company". There is also information that the Fiat foundry used an alloy of $6 \% \mathrm{Si}, 2 \% \mathrm{Cu}, 0.3 \%$ $\mathrm{Mn}$, i.e. AK52 (4.0-6.0\% Si, 1.5-3.5\% Cu, 0.3-0.8\% Mg, $0.2-0.8 \mathrm{Mn}, 0.5 \mathrm{Ni}$ ) for the engine block.

According to [15] and [2], A356.0 aluminum alloy (ASTM: $6.5-7.5 \% \mathrm{Si}, 0.2 \% \mathrm{Cu}, 0.25-0.45 \% \mathrm{Mg}, 0.1 \% \mathrm{Mn}$ ) is a widely used material in the production of cylinder heads of internal combustion engines. In the old Polish standard $\mathrm{PN}-76 / \mathrm{H}-88027$ it is an alloy marked as AK7 (6.0-8.0\% Si, $0.2 \% \mathrm{Cu}, 0.25-0.4 \% \mathrm{Mg}, 0.1-0.5 \mathrm{Mn}$ ), while in the European standard: AlSi7Mg0.3.

\subsection{Overview of research carried out with \\ the application of selected aluminum alloys}

This review has focused on the aluminum alloys that are used for CI engine blocks and on the materials considered for such applications. The main conclusions of this work were selected, focusing on the material properties relevant to the critical load conditions of the engine block. 
In the paper [2] the influence of T6 type heat treatment of AK7 alloy on thermo-mechanical fatigue and cyclic slow-changing loads was investigated. In experimental studies an improvement in mechanical and slow-changing loads, especially at room temperature, was found. However, the positive effect of heat treatment on thermo-mechanical stability was not so significant anymore and the difference in strength between the alloy with and without heat treatment decreased with the increase in temperature. The authors conclude that heat treatment did not improve thermomechanical fatigue properties of the alloy due to overaging, i.e. softening of the alloy due to exceeding the required temperature or the required artificial aging time, while under isothermal load the strength properties improved significantly.

In the paper [15] the influence of the artificial ageing process on the material samples taken from the cylinder head made of AK7 aluminum alloy and thermally treated with T6 type was investigated. The effects of thermal slowchanging loads and changes in the microstructure during the thermal fatigue test were studied. Under conditions corresponding to the operation of the engine, thermal strength tests of slow-changing loads were carried out in order to describe the nature of elastic, plastic and viscoelastic deformations and thermal fatigue. An important conclusion obtained by the authors of the paper is the fact of improving fatigue life after the application of ageing after heat treatment type $\mathrm{T} 6$, but at the same time the strength decreased and the material showed a tendency to deformation. The ageing time also influences the strength properties and enables optimization of fatigue strength.

In the paper [12] the fatigue properties of the alloy marked as ASTM A357.0, heat-treated type T61, composed of $6.5-7.5 \% \mathrm{Si}, 0.2 \% \mathrm{Cu}, 0.4-0.7 \% \mathrm{Mg}, 0.1 \% \mathrm{Mn}$, which corresponds to the Polish standard PN-76/H-88027 AK7 alloy (EN: AlSi7Mg0.6), however with a slightly higher magnesium content than A356, were studied. This alloy is used for the production of cylinder heads of diesel engines. The authors pay attention to material defects, such as porosity or oxide coating, which may be the initiators of damage if located on the surface or in the top layer of the cast elements.

The article [12] presents the results of investigations carried out in terms of fatigue strength and micromechanisms of damage on a sample obtained from a new cylinder head taken immediately after leaving the production line. A relationship between the fatigue zone micromechanism and final failure zone and the appearance of fatigue cracks in the area of porosity defect was observed on the surface of the specimen fracture. The main initiator of fatigue crack was the surface porosity in the region of maximum tensile stress. When porosity occurred outside this area, far from the maximum tensile stress, it did not crack the specimen. Other factors such as oxide inclusions, silicon particle size, intermetallic iron molecules did not affect fatigue life due to the predominance of pores previously initiating fractures. This statement is consistent with the results of the paper [3], in which the authors state that porosity is the main factor defining fatigue life of aluminum alloys.
In the paper [7] various aluminum alloys with the following determination were subjected to fatigue tests: $\mathrm{AlSi7Mg}$ T6 (A356), AlSi5Cu3-T7, AlSi5Cu1-T7, AlMg3Si1-T6, AlMg3Si1(Cu)-T6 and AlMg3Si1(Sc,Zr)-T5. The first one is the most commonly used alloy for cylinder heads and is a reference point for the other materials in the context of their use for cylinder heads. Cast aluminum cylinder heads are subjected to increasing thermo-mechanical loading and the space between valve bridge is a critical element. For this reason, the sample geometry was modified (Fig. 2), similar to that of the critical element, and compared to the load model obtained on standardized samples.

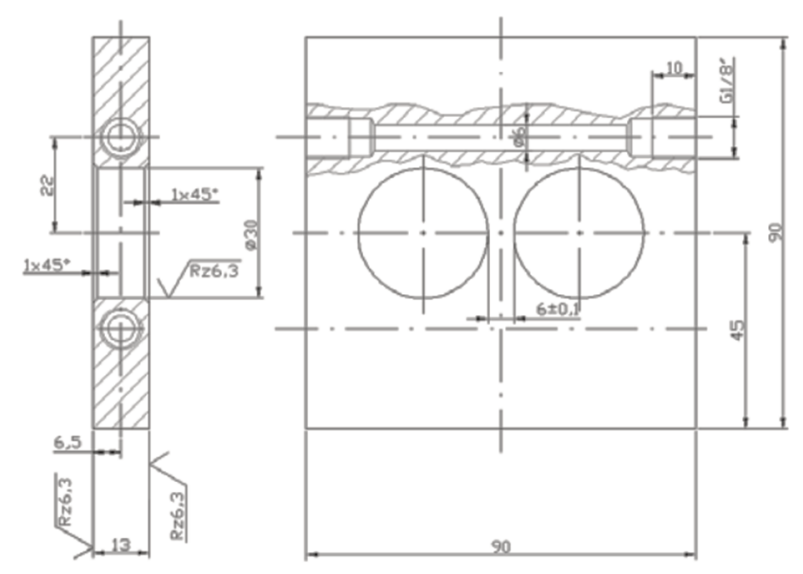

Fig. 2. View of the sample [7]

On the basis of experimental research it has been proposed to build in a numerical ageing model of the alloy in order to improve the model used to determine fatigue life. The cylinder head is exposed to multi-axial loads and varying temperature conditions, but cracks are initiated around the valve seat. The strength of aluminum alloys decreases significantly with increasing temperature. Hardened alloys reduce their strength already at $150-200^{\circ} \mathrm{C}$, which also affects the metallurgical properties and microstructure. The local load on the head is in the range of $20-300^{\circ} \mathrm{C}$. The anticipation of a decrease in material strength allows the serious consequences of damage to be limited. The lowest coefficient of thermal expansion was obtained for standard alloy A356, regardless of temperature increase. The thermal conductivity of this alloy tested at $50-400^{\circ} \mathrm{C}$ was also the highest $(190 \mathrm{~W} /(\mathrm{mK}))$. The mechanical strength of almost all the tested alloys decreases drastically in the range 150$250^{\circ} \mathrm{C}$ (from about 300-350 MPa to 150-200 MPa), except for the alloy AlMg3Si1(ScZr)-T5, for which the value of permissible stresses remains at the level of 250-300 MPa throughout the temperature range investigated [7].

Despite the fact that the aluminum alloys with the main additives such as silicon and copper $(\mathrm{AlSiCu})$ are characterized by high thermal conductivity, the decrease in strength was not as significant as in the case of the standard alloy A356. The tested aluminum alloys with magnesium and silicon (AlMgSi), despite worse strength and thermal conductivity, were able to withstand up to twice as many thermal-mechanical load cycles to crack than the standard alloy. The studies carried out clearly indicate the influence of aging of the material on tensile strength and stress distribu- 
tion associated with a variable temperature field. Determination of the function, which will include thermal load during the heat-resistance tests, will enable a more accurate forecast of the product life under real load conditions. The properties of alloys as a function of time, temperature and the number of fatigue cycles were also determined. An important conclusion from the study is the size of the influence of the ageing temperature on the two tested alloys. In the case of the standard alloy it is high, whereas in the case of AlMg3Sil ( $\mathrm{Sc}, \mathrm{Zr}$ ) - T5 alloy it is low and even imperceptible. The research has also shown higher resistance of $\mathrm{AlSiCu}$ alloys to crack initiation in comparison to $\mathrm{AlMgSi}$ and AlSiMg alloys. Several numerical simulations for $\mathrm{AlSi} 7 \mathrm{Mg}$ and AlSi5Cu3 alloys were carried out and compared with experimental results. Consideration of material aging function in the model turned out to be important especially for the standard alloy, which properties deteriorate drastically in the range of applied thermal loads [7].

\section{Conclusions}

It was concluded that it is not appropriate to use for the prototype engine block an alloy which is not commercially available. Production of a new alloy in a foundry, only for the purpose of making a prototype engine is not economically justified and, moreover, makes it necessary to deter- mine its material data. It should be mentioned that the aim of the project is the construction of a new engine and therefore testing of new materials exceeds the scope. It is worth mentioning that the information presented in the material databases, i.e. that the physical and mechanical specifications given are only approximations, and the properties of materials may vary significantly depending on the supplier, internal standards, heat treatment, dimensions and other parameters, therefore there is no guarantee of suitability for a specific application.

It is recommended to use the alloy marked AK7 (A356, $\mathrm{AlSi} 7 \mathrm{Mg}$ ) for the production of the prototype engine block. If the results of simulation studies will indicate the correctness of the selection, and the manufactured element will not show sufficient strength, the cause of the damage should be determined and perhaps another technology of production should be considered, with particular attention on the porosity of the produced element.

\section{Acknowledgements}

This work has been realized in the cooperation with The Construction Office of WSK "PZL-KALISZ" S.A." and is part of Grant Agreement No. POIR.01.02.00-00-0002/15 financed by the Polish National Centre for Research and Development.

\section{Bibliography}

[1] ASHBY, M.F. Dobór materiałów w projektowaniu inżynierskim, red. Wojciechowski S.M., WNT, Warszawa 1998.

[2] AZADI, M., MEHDI M.S. Heat treatment effect on thermomechanical fatigue and low cycle fatigue behaviors of A356.0 aluminum alloy. Materials\&Design. 2013, 45, 279285. DOI:10.1016/j.matdes.2012.08.066.

[3] BUFFIERE, J.Y. et al. Experimental study of porosity and its relation to fatigue mechanisms of model Al-Si7-MgO.3 cast al alloys. Materials Science and Engineering: A. 2001, 316. DOI:10.1016/S0921-5093(01)01225-4.

[4] CZYŻ, Z., SIADKOWSKA, K., SOCHACZEWSKI, R. CFD analysis of charge exchange in an aircraft opposedpiston diesel engine. MATEC Web of Conferences. 2019, 252, 04002. DOI:10.1051/matecconf/201925204002.

[5] GRABOWSKI, Ł., PIETRYKOWSKI, K., KARPIŃSKI, P. Charging process analysis of an opposed-piston two-stroke aircraft diesel engine. ITM Web of Conferences. 2017, 15, 03002. DOI:10.1051/itmconf/20171503002.

[6] Forum Aluminium. Oznaczenia stanów produktów. 2016, $\mathrm{http} / / /$ forumaluminium.pl/pl/forum/6/topic $=16$.

[7] GRIEB, M.B. et al. Thermomechanical fatigue of cast aluminium alloys for cylinder head applications experimental characterization and life prediction. Procedia Engineering. 2010, 2 (1), 1767-1776. DOI:10.1016/j.proeng.2010.03.190.

[8] Investa. Tabela gatunków stopów aluminium. 2017, http://www.investa.pl/oferta/aluminium_poradnik_tabela_ga tunkow.html.

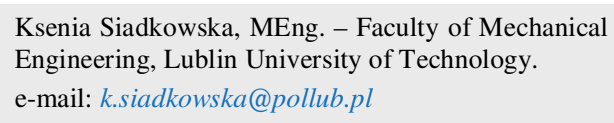

[9] KONIECZNY, J. Materiały stosowane w konstrukcjach lotnictwa wojskowego. Armia. 2013, 4, 68-75.

[10] Konsorcjum Biocentrum Ochota. Odlewnicze stopy aluminium wg PN-EN 1706:2001. 2017, http://info.grafen.ippt. pan.pl/bazy/bazy-materialowe/aluminium.html.

[11] MAGRYTA, P., PIETRYKOWSKI, K.,SKIBA, K. FEM simulation research of natural frequency vibration of crankshaft from internal combustion engine, ITM Web of Conferences. 2017, 15, 07004. DOI: 10.1051/itmconf/20171507004.

[12] MATTOS, J.J.I. et al. Fatigue properties and micromechanism of fracture of an $\mathrm{AlSiMg0.6}$ cast alloy used in diesel engine cylinder head. Procedia Engineering. 2010, 2(1), 759-765. DOI:10.1016/j.proeng.2010.03.082.

[13] ORŁOWICZ, W., OPIEKUN, Z. Badania materiałowe odlewów głowic silników. Solidification of Metals and Alloys. 1998, 38, 97-102.

[14] SZCZECIŃSKI, S. Transactions of the Institute of Aviation - Aircraft Powerplant Issues. 2009, 4(199).

[15] TAKAHASHI, T., KATSUHIKO S. Low cycle thermal fatigue of aluminum alloy cylinder head in consideration of changing metrology microstructure. Procedia Engineering. 2010, 2(1), 767-776, DOI:10.1016/j.proeng.2010.03.083.

[16] TULWIN, T., KARPIŃSKI, P. Analysis of the fuel spray diversity in the opposed-piston engine, IOP Conf. Series: Journal of Physics: Conf. Series. 2018, 1101, 012045 DOI:10.1088/1742-596/1101/1/012045.

[17] WACH, J. Dobór materiałów konstrukcyjnych. 2017, http://fluid.itcmp.pwr.wroc.pl/ jwach/lab/mkie.htm.

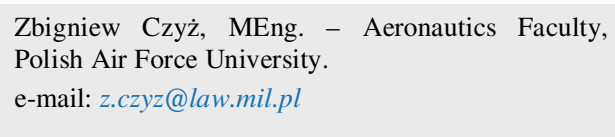

e-mail: z.czyz@law.mil.pl

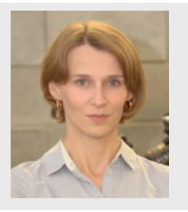

